\title{
A tradução de marcadores culturais em Sargento Getúlio à luz da lingüística de corpus
}

\author{
Elisangela Fernandes Martins (MARTINS, Elisangela F.) \\ Mestre em Estudos Lingüísticos pela Universidade Estadual Paulista - UNESP/IBILCE \\ parreirakid@terra.com.br \\ Diva Cardoso de Camargo (CAMARGO, Diva C.) \\ Professora Doutora da Universidade Estadual Paulista - UNESP/IBILCE \\ diva@ibilce.unesp.com.br
}

\section{Resumo}

Este artigo aborda a tradução de marcadores culturais em Sergeant Getulio em relação ao seu original Sargento Getúlio, ambos do escritor e autotradutor João Ubaldo Ribeiro. A fundamentação teórica apóia-se nos Estudos da Tradução baseados em corpus de Baker e de Camargo, na Lingüística de Corpus de Berber Sardinha, nos trabalhos sobre domínios culturais de Nida e de Aubert, e na proposta das modalidades tradutórias reformuladas por Aubert. Quantos aos procedimentos metodológicos, usamos as ferramentas de busca disponibilizadas pelo programa WordSmith Tools, versão 4.0. Os resultados obtidos revelam que João Ubaldo Ribeiro busca uma maior aproximação entre o leitor de língua inglesa e a mensagem do original por meio do uso de recursos da modulação, da explicitação e da adaptação ao traduzir, para o inglês, marcadores culturais específicos da realidade brasileira.

Palavras-chave: marcador cultural, lingüística de corpus, estudos da tradução baseados em corpus, João Ubaldo Ribeiro.

\begin{abstract}
This article analyses the translation of cultural markers in Sergeant Getulio in relation to the original text Sargento Getúlio, both by the author and self-translator João Ubaldo Ribeiro. The theoretical approach rests on Corpus-Based Translation Studies of Baker and Camargo, Corpus Linguistics of Berber Sardinha, cultural domain studies of Nida, and translation modalities of Aubert. The methodological procedure applied for word extraction was the WordSmith Tools program, version 4.0. The results suggest that João Ubaldo Ribeiro seeks to bring the reader of the English text closer to the source text by using modulations, explicitations and adaptations to translate specific Brazilian cultural markers into the English language and culture.
\end{abstract}

Keywords: cultural marker, corpus linguistics, corpus-based translation studies, João Ubaldo Ribeiro. 


\section{Introdução}

A tradução, notadamente a literária, envolve questões que vão além da simples transmissão de informação. Busca-se recuperar todo o contexto situacional, temporal, estilístico e cultural do texto de partida, adequando-os às condições permitidas pela língua e cultura de chegada. As dificuldades do ato tradutório intensificam-se no caso de traduções entre línguas que expressam realidades extralingüísticas mais distantes.

O presente trabalho analisa marcadores culturais (MCs) presentes em uma obra importante da literatura brasileira: Sargento Getúlio, publicada em 1971 e traduzida para o inglês em 1978, pelo próprio autor, João Ubaldo Ribeiro. Os MCs apresentam desafios ao tradutor por trazerem marcas da cultura de partida que, muitas vezes, são parcial ou totalmente desconhecidos na língua e cultura de chegada, dado que remetem a um conjunto de valores e de padrões de comportamentos, bem como a realidades extralingüísticas referentes a domínios ecológicos, materiais, sociais e ideológicos.

Além das dificuldades que envolvem a tradução cultural, justifica-se também essa pesquisa pela importância da obra que rendeu ao escritor o prêmio Jabuti como revelação de autor, e por ter sido traduzida para o inglês pelo próprio João Ubaldo Ribeiro.

\section{Fundamentação teórica}

Para a realização deste estudo, apoiamo-nos na abordagem interdisciplinar adotada por Camargo (2005, 2007), que se fundamenta nos Estudos da Tradução Baseados em Corpus (BAKER, 1993, 1996) e na Lingüística de Corpus (BERBER SARDINHA, 2004). Recorremos também aos trabalhos sobre domínios culturais de Nida (1945), e sua reformulação por Aubert (1981, 2006), e aos estudos sobre modalidades tradutórias de Aubert $(1984,1998)$ para a investigação de MCs. A investigação também faz uso de ferramentas eletrônicas disponibilizadas pelo programa computacional WordSmith Tools, para a investigação do corpus e levantamento dos dados.

Baker (1993) lançou a proposta da investigação em corpora de textos traduzidos, enfatizando que:

textos traduzidos registram eventos de comunicação genuínos e como tais não são nem inferiores nem superiores aos outros eventos comunicativos em qualquer língua. Entretanto, eles são diferentes, e a natureza dessa diferença precisa ser explorada e registrada. ${ }^{1}$ (BAKER, 1993, p. 234)

A Lingüística de Corpus tem oferecido importantes contribuições para os estudos da tradução ao permitir a investigação de características típicas da linguagem da tradução por meio da observação de dados reais e evidências empíricas encontradas nos textos de chegada.

\footnotetext{
${ }^{1}$ (Todas as traduções são de nossa autoria). Texto original: Translated texts record genuine communicative events and as such are neither inferior nor superior to other communicative events in any language. They are however different, and the nature of this difference needs to be explored and recorded.
} 
Com relação à Lingüística de Corpus, Berber Sardinha explica que “ela ocupase da coleta e da exploração de corpora, ou conjunto de dados lingüísticos textuais coletados criteriosamente, com o propósito de servirem para a pesquisa de uma língua ou variedade lingüística” (BERBER SARDINHA, 2004, p. 3).

Para uma definição de corpus, Berber Sardinha considera:

Um conjunto de dados lingüísticos (pertencentes ao uso oral ou escrito da língua, ou a ambos), sistematizados segundo determinados critérios, suficientemente extensos em amplitude e profundidade, de maneira que sejam representativos da totalidade do uso lingüístico ou de algum de seus âmbitos, dispostos de tal modo que possam ser processados por computador, com a finalidade de propiciar resultados vários e úteis para a descrição e análise. (BERBER SARDINHA, 2004, p. 18)

Para a realização deste trabalho, foi utilizado um corpus paralelo, que corresponde ao nosso corpus de estudo (formado pela obra original e sua respectiva tradução), também usamos um corpus de referência de língua portuguesa, o LACIO REF, do NILC, o qual se encontra detalhado no item "Material e procedimentos metodológicos".

O corpus paralelo é definido por Baker como contendo:

textos em determinada língua de origem A e suas versões traduzidas em língua B. [Este tipo de corpus] permite estabelecer, objetivamente, como os tradutores superam dificuldades de tradução na prática e como utilizam essas evidências para fornecer modelos autênticos no treinamento de tradutores. (BAKER, 1995, p. 230-231) $)^{2}$

Quanto ao corpus de referência, segundo Berber Sardinha:

Também é conhecido como corpus de controle, e funciona como termo de comparação para a análise. A sua função é fornecer uma norma com a qual se fará a comparação das freqüências do corpus de estudo. A comparação é feita por meio de uma prova estatística selecionada pelo usuário (qui-quadrado ou log-likelihood). As palavras cujas freqüências no corpus de estudo forem significativamente maiores segundo o resultado da prova estatística são consideradas chave, e passam a compor uma listagem de palavras-chave. ${ }^{3}$ (BERBER SARDINHA, 2004, p. 97)

No que tange aos MCs, correspondem a vocábulos ou expressões que representam elementos inseridos em uma determinada cultura, e que revelam realidades específicas do ponto de vista ecológico, material, social e ideológico. Tais peculiaridades sócio-culturais variam de povo para povo, de país para país ou de região para região (AUBERT, 1981, p. 2).

Para uma investigação dos MCs, a proposta de Nida (1945) possibilita uma classificação por domínios culturais. Para o uso em pesquisa, Aubert (1981) sugere uma

\footnotetext{
${ }^{2}$ Texto original: A parallel corpus consists of original, source language-texts in language A and their translated versions in language B. They allow us to establish, objectively, how translators overcome difficulties of translation in practice, and to use this evidence to provide realistic models for trainee translators.

${ }^{3}$ Destaque do autor.
} 
reformulação da proposta de Nida para facilitar a classificação dos MCs. Para tanto, Aubert (1981, p. 40-41) considera quatro domínios culturais, a saber:

1 - Domínio da cultura ecológica: vocábulos designando seres, objetos e eventos da natureza, em estado natural ou aproveitados pelo homem, desde que o conteúdo intrínseco do vocabulário não implique em que seja ser, objeto ou evento que tenha sofrido alteração pela ação voluntária do homem. Podemos citar como exemplos: curimã, embira, mucuim; ${ }^{4}$

2 - Domínio da cultura material: vocábulo designando objetos criados ou transformados pela mão do homem, ou atividades humanas. São exemplos: reiúnas, patacho, mundéu;

3 - Domínio da cultura social: vocábulos que designam o próprio homem, suas classes, funções sociais e profissionais, origens, relações hierárquicas, bem como as atividades e eventos que estabelecem, mantêm ou transformam estas relações, inclusive atividades lingüísticas. Podemos citar como exemplos: arretado, cabra safado, peste;

4 - Domínio da cultura ideológica: vocábulos que designam crenças, sistemas mitológicos, e as entidades espirituais que fazem parte desses sistemas, bem como as atividades e eventos gerados por tais entidades. São exemplos: caipora, manjaléu, cão.

Recorremos também aos estudos sobre modalidades tradutórias de Aubert (1984, 1998) pela necessidade de adotarmos uma classificação para os MCs com base em critérios lingüístico-tradutórios que permitissem uma observação mais detalhada sobre as soluções propostas pelos tradutores. Os estudos sobre modalidades tradutórias tiveram origem em Vinay e Dalbernet $(1958,1977)$ e Vinay (1968). Contudo, os dois teóricos canadenses propuseram um modelo que apresenta lacunas em determinadas modalidades de tradução, tornando difícil a classificação para o pesquisador. Aubert (1984, 1998) sugere, então, uma reformulação da proposta, contendo definições mais precisas. A nova proposta compõe-se de duas categorias: a tradução direta (que envolve cinco modalidades: transcrição, empréstimo, decalque, tradução literal e transposição); e a tradução indireta (que envolve cinco modalidades: explicitação, implicitação, modulação, adaptação e tradução intersemiótica). Há ainda quatro tipos de modalidades que não se enquadram nas duas categorias: a omissão, a correção, o erro e o acréscimo.

A distribuição das modalidades apresenta uma gradação de dificuldades do ato tradutório, desde o "grau zero" da tradução, até o "grau máximo”, que corresponde ao limite do intraduzível. O empréstimo, em um dos extremos, representa "uma mera transcrição de um segmento do original” (AUBERT, 1984, p. 74); no outro extremo da escala dessa gradação está a adaptação, "representando uma tentativa de assegurar não mais uma equivalência, mas apenas um certo grau de semelhança entre as duas situações, cada qual privativa de um dos complexos sócio-culturais em confronto.” (AUBERT, 1984, p. 75). Apresentamos, abaixo, apenas a definição das modalidades tradutórias ${ }^{5}$ que foram usadas para a classificação dos MCs neste trabalho:

1 - Explicitação: informações implícitas no texto de partida tornadas explícitas no texto de chegada.

2 - Modulação: ocorre quando há deslocamento no nível semântico ou estilístico, mais ou menos profundo, devido a mudanças de ponto de vista, sem, contudo, mudar a significação.

3 - Adaptação: ocorre na tentativa de assemelhar duas situações de diferentes complexos sócio-culturais, o da língua de partida e o da língua de chegada.

\footnotetext{
${ }^{4}$ Exemplos extraídos do subcorpus Sargento Getúlio.

${ }^{5}$ Para uma definição mais completa das modalidades, ver Aubert (1998, p. 105-110), Camargo (1993).
} 


\section{Material e procedimentos metodológicos}

As obras foram escaneadas e revisadas utilizando-se o OCR (Optical Character Recognition) e, também, o corretor ortográfico do Word. Os textos foram salvos em formato "txt" para que pudessem ser processados pelo programa computacional.

Também foi usado um corpus de referência em língua portuguesa, obtido no site do NILC (Núcleo Interinstitucional de Linguística Computacional), desenvolvido na USP de São Carlos, o qual está disponível para pesquisadores da área. Esse corpus é constituído por textos das áreas: biológica, social, religião e pensamento, saúde, exatas, generalidades, humanas, e agrárias.

O programa utilizado nesta pesquisa foi o WordSmith Tools (Software para Windows 98 e XP, versão 4.0, desenvolvido por Mike Scott e comercializado pela Oxford University Press). O programa, que funciona com base em três princípios básicos: a ocorrência, a recorrência e a coocorrência, disponibiliza três ferramentas de busca: WordList, KeyWord e Concord.

A ferramenta WordList gera uma lista de palavras contidas no texto, ordenadas pela freqüência ou alfabeticamente. Para este estudo, foram extraídas três listas de palavras, uma do texto de partida Sargento Getúlio, uma do texto de chegada Sergeant Getulio, e uma do corpus de referência da língua portuguesa.

Com a ferramenta Keyword, geramos duas listas de palavras-chave a fim de poder estabelecer um contraste entre as palavras dos respectivos textos originais com as palavras do corpus de referência.

Com a ferramenta Concord, produzimos listas de concordâncias dos MCs acompanhados do seu co-texto para observar o sentido com que foram empregadas nas respectivas obras.

Desse modo, a partir da lista de palavras-chave, verificamos no Novo Aurélio O Dicionário da Língua Portuguesa, e no Dicionário do Folclore Brasileiro, os vocábulos que são considerados brasileirismos e indicadores de MCs. A seguir, os MCs foram classificados de acordo com os quatro domínios sugeridos por Aubert (1981, p. 40-41).

Geramos, então, cinco tabelas para apresentar os resultados da análise. A primeira apresenta a distribuição dos marcadores por domínios culturais da obra Sargento Getúlio; as tabelas 2, 3, 4 e 5 apresentam as opções de tradução para MCs classificados por domínios culturais. Para procedermos às análises das traduções, recorremos ao Dicionário Inglês-Português - Houaiss e ao Dicionário Longman.

\section{Análise de marcadores por domínios culturais}

Os marcadores culturais classificados por domínios culturais revelam temas e sub-temas da obra. Para melhor ilustrar a distribuição dos MCs extraídos da obra Sargento Getúlio, montamos a Tabela 1, que apresenta, na primeira coluna, o domínio cultural; na segunda, a porcentagem que cada domínio representa do conjunto de marcadores extraídos da obra; e na terceira, a quantidade de MCs de cada domínio. 


\section{TABELA 1 - DISTRIBUIÇÃO DOS MARCADORES POR DOMÍNIOS CULTURAIS}

\begin{tabular}{c|c|c}
\hline Domínios Culturais & \% da distribuição & $\begin{array}{c}\text { Quantidade de } \\
\text { marcadores }\end{array}$ \\
\hline Social & 39,22 & 60 \\
\hline Ecológico & 35,29 & 54 \\
\hline Material & 22,88 & 35 \\
\hline Ideológico & 2,61 & 4 \\
\hline Total & 100 & 157 \\
\hline
\end{tabular}

Como podemos observar na tabela acima, o aspecto social é o mais marcante na obra em análise, apresentando a maior quantidade de MCs (39,22\%). O domínio ecológico também apresenta grande quantidade de MCs (35,29\%). O domínio material é representado por quantidade moderada de marcadores (22,88\%). Já o domínio ideológico, apresenta quantidade muito pequena de marcadores (2,61\%).

Os domínios social e ideológico se sobrepõem muitas vezes, dificultando a classificação, pois ambos pressupõem a visão do homem sobre o mundo e suas idéias. Suas crenças se refletem na sociedade, e por outro lado, a sociedade interfere em sua visão do mundo. Para tirar ambigüidade dessas questões, Aubert (1981, p. 41) propõe que sejam considerados ideológicos apenas os MCs que designam crenças relacionadas à religião, sistemas mitológicos, ou que estejam relacionados a eles. Por essa razão, os vocábulos presentes na obra que se classificam como MCs do domínio ideológico são poucos, uma vez que a carga ideológica dada pelo autor está relacionada ao domínio social, à visão do homem sobre o próprio homem e seu comportamento, e não a entidades espirituais.

No entanto, é possível, dentro de contextos diferentes, ao longo do livro, observar vocábulos que podem ser classificados como pertencentes a mais de um domínio. Podemos citar, como exemplo, o vocábulo "bicho", que ora pode ser classificado no domínio ecológico, por referir-se ao bicho-de-pé, e ora pode ser classificado no domínio ideológico, por referir-se ao diabo.

Para análise, selecionamos em cada domínio os MCs que apresentam os maiores índices de chavicidade. Iniciamos pelo domínio social por ser o que apresenta maior quantidade de marcadores. Na Tabela 2, apresentamos os MCs no texto de partida (na primeira coluna), o número de ocorrências (na segunda coluna), as opções de tradução para os MCs (na terceira coluna), e o número de ocorrências de cada opção de tradução (na quarta coluna).

\section{TABELA 2 - OPCÕES DE TRADUÇ̃̃O PARA MCs DO DOMÍNIO SOCIAL}

\begin{tabular}{l|c|l|c}
\hline $\begin{array}{c}\text { MCs em Sargento } \\
\text { Getúlio }\end{array}$ & Ocorrências & MCs em Sergeant Getulio & Ocorrências \\
\hline CABOVERDE & 4 & BLACK & 2 \\
& & SMOOTH-HAIRED BLACK & 2 \\
\hline TABARÉU & 1 & HICK & 1 \\
\hline JAGUNÇO & 1 & BAD MAN & 1 \\
\hline MOENDEIRO & 1 & THE OWNER OF A SUGAR & 1 \\
\hline ABOIO & 6 & CANE FIELD & 4 \\
\hline
\end{tabular}




\begin{tabular}{l|c|l|c}
\hline & & CHANT & 2 \\
\hline CANGAÇO & 8 & BANDITRY & 3 \\
& & BANDIT & 5 \\
\hline PORRETA & 2 & LOVELY & 1 \\
& & IMPORTANT LOOKING & 1 \\
\hline FROUXO & 7 & LILY-LIVERED & 1 \\
& & COWARDILY & 2 \\
& & SPINLESS & 1 \\
& & YELLOW & 3 \\
\hline FROUXIDÃO & \multirow{2}{*}{4} & YELLOWNESS & 1 \\
& & WAVERING & 1 \\
& & COWARDICE & 1 \\
& & WEAKNESS & 1 \\
\hline
\end{tabular}

Os MCs “caboverde" e "tabaréu” estão relacionados a origens e condições sociais. O marcador "caboverde”, segundo o dicionário Novo Aurélio, é usado para designar o mestiço de negro e índio, e na obra traduzida correspondem às formas: black e smooth-haired black, traduzidas respectivamente por meio de modulação e de explicitação com modulação.

“Tabaréu” é um vocábulo de origem tupi usado para representar o caipira, traduzido por hick, significando aquele que habita o campo ou a roça; é o indivíduo sem instrução e de convívio rústico, sem traquejo social. Na obra em estudo, o caipira, e o sertanejo, são vistos como fracassados; o narrador personagem se sente vitorioso por ter se transformado de sertanejo em jagunço político. A opção adotada pelo tradutor representa também uma pessoa sem instrução; porém, tabaréu tem conotação mais negativa do que hick.

Os MCs “jagunço”, "moendeiro”, “aboio” e “cangaço” estão relacionados a atividades desenvolvidas pelos nordestinos. O marcador "jagunço" refere-se ao capanga; segundo o Novo Aurélio, designa o indivíduo valentão que se coloca a serviço de quem lhe paga. É uma figura marcante do tempo do coronelismo, onde os grandes proprietários conseguiam fazer valer as próprias regras por meio da força. Para "jagunço", o tradutor optou pela modulação bad man, que resgata traços importantes da personalidade desse indivíduo. O "moendeiro", também conhecido por moleiro, é o proprietário de um moinho; para traduzi-lo, foi empregada a modalidade de explicitação: the owner of a suger cane field, provavelmente por não haver um vocábulo que transmita a carga semântica de "moendeiro" em inglês. O cultivo da cana-de-açúcar e toda a atividade que ela envolve são comuns no Brasil. O "aboio", traduzido como cattle chant ou apenas por chant, é definida no dicionário Novo Aurélio como o canto monótono com que os vaqueiros guiam as boiadas ou chamam os bois dispersos, atividade muito comum no nordeste brasileiro. A palavra chant está relacionada mais comumente a cantos religiosos, mas o tradutor usou cattle, que significa "boiada” para explicitar seu sentido. "Cangaço" ou "cangaceirismo" diz respeito ao gênero de vida dos cangaceiros. O cangaceiro é "um criminoso errante, isolado ou em grupo, vivendo de assaltos e saques, perseguido, e perseguindo, até a prisão ou a morte numa luta com tropa da polícia ou com outro bando de cangaceiros” (Dicionário do Folclore Brasileiro ${ }^{6}$ ). Distingue-se do bandit na cultura de chegada que tem como objetivo principal o produto do roubo. O “cangaceiro" é levado ao crime por

${ }^{6}$ Disponível no site: <http://www.terrabrasileira.net/folclore/regioes/7tipos/cangaço.html>. 
motivos que variam, desde uma tendência criminosa de sua personalidade, até motivos ideológicos motivados pela sugestão irradiante dos grandes cangaceiros que lutavam por diversas causas. Alguns eram adorados pela população pobre, como o caso de Jesuíno Brilhante; eram tidos como defensores dos fracos, corajosos; e eram incapazes de violência contra moças e crianças. Por outro lado, alguns eram temidos por todos por serem brutais, como o caso de Lampião. O bandit apresenta alguns traços em comum com o "cangaceiro", por exemplo, andar em bando, sempre fortemente armado e roubar; no entanto, não representa o mesmo papel nos respectivos contextos sócioculturais. Para recuperar o marcador “cangaceiro”, o autotradutor recorreu à modalidade da modulação ou explicitação com modulação, usando as formas bandit e banditry no texto de chegada.

"Porreta”, "frouxo" e "frouxidão" são MCs que representam conceitos importantes para o nordestino. O primeiro, recuperado pela modulação important looking e lovely, diz respeito a coisas boas, excelentes, muito bonitas. "Frouxo" e "frouxidão" estão relacionados fortemente à temática da obra. Segundo Miyasaki (1996, p. 21), o narrador personagem, Sargento Getúlio, em seu monólogo, apresenta seu universo masculino, que se divide em dois sistemas: o do medo/coragem e o da vergonha/honra. Esses dois vocábulos fazem parte de um pequeno paradigma de qualificações usado pelo narrador, em que tudo tem de ser classificado: ou o indivíduo é "valente", "macho" (coragem e honra), ou é "frouxo" (medo e vergonha). Esses MCs foram traduzidos de várias formas: lily-livered, cowardily, spineless e yellow para "frouxo", e yellowness, wavering, cowardice e weakness para "frouxidão". Percebemos que o tradutor recorreu a várias formas de tradução para recuperar o sentido desses dois MCs, provavelmente porque não encontrou um correspondente em língua inglesa que pudesse exprimir toda a carga semântica de "frouxo" e "frouxidão". As modulações cowardily, lily-livered, yellow, yellowness e cowardice remetem ao sentido de covardia expressado pelo marcador. As opções wavering e weakness podem, também, ser consideradas modulações, pois remetem respectivamente à indecisão e fraqueza, de acordo com o dicionário Houaiss Inglês-Português.

Para o domínio ecológico, selecionamos os MCs "caatinga”, "catanduvas", "sertão”, “guará”, “fogopagou”, “gaiamum”, “quixabeira”, “macambira”, e “mandacaru”, conforme mostra a Tabela 3, a seguir:

\section{TABELA 3 - OPCÕES DE TRADUCÃO PARA MCs DO DOMÍNIO ECOLÓGICO}

\begin{tabular}{l|c|l|c}
\hline $\begin{array}{c}\text { MCs em Sargento } \\
\text { Getúlio }\end{array}$ & Ocorrências & MCs em Sergeant Getulio & Ocorrências \\
\hline CAATINGA & 3 & WASTLAND & 1 \\
& & DROUGHT FOREST & 1 \\
& & BADLANDS & 1 \\
\hline CATANDUVAS & 3 & VINES & 1 \\
& & GROUND VINES & 2 \\
\hline SERTÃO & 8 & BACKLANDS & 7 \\
& & ROUGH COUNTRY & 1 \\
\hline GUARÁ & 1 & WILD DOG & 2 \\
\hline FOGOPAGOU & 3 & SCALED DOVE & 1 \\
\hline
\end{tabular}




\begin{tabular}{l|l|l|l}
\hline GAIAMUM & 3 & LAND CRAB & 3 \\
\hline QUIXABEIRA & 1 & BUMELIA & 1 \\
\hline MACAMBIRA & 3 & BROWN BUSHES & 3 \\
\hline MANDACARU & 2 & CACTUS & 2 \\
\hline
\end{tabular}

Os três primeiros referem-se à vegetação rústica nordestina; remetem a uma imagem de vegetação seca, sem folhas, quase sem vida, mas há diferenças entre eles. Conforme o Novo Aurélio, "sertão" refere-se à área pouco povoada do interior do Brasil, mais seca do que a caatinga, onde prevalece a criação de gado sobre a agricultura, e onde perduram tradições e costumes antigos; a "caatinga” corresponde a um tipo de vegetação característica do nordeste brasileiro, formado por pequenas árvores, comumente espinhosas, que perdem as folhas no curso da longa estação seca; “catanduvas" também conhecida como "catanduba”, de origem tupi, refere-se ao mato rasteiro e espinhento. $\mathrm{O}$ tradutor recorreu a mais de uma forma para recuperar o sentido de cada uma delas. "Caatinga" foi traduzida por meio da modulação wastland, e badlands, e por explicitação com drought forest. Essas três opções representam tipos diferentes de vegetação da cultura de chegada. Wastland não consta no dicionário Houaiss Inglês-Português que utilizamos nesta pesquisa; pode ter ocorrido, um erro de digitação, dado que a forma correta deste vocábulo é wasteland, que segundo o dicionário, refere-se ao deserto e à terra inculta; badlands corresponde a "terras áridas com formações erosivas fantásticas e platôs quase horizontais, voçoroca”; e forest é definida como "floresta, selva, bosque, mata, região destinada à caça em geral. Drought, definido como seca ou estiagem, complementa o sentido de forest procurando dar a ela características do ambiente nordestino.

Para "catanduvas", o autotradutor optou pela explicitação ground vines, e pela modulação vines, definida no dicionário Novo Aurélio como "mato rasteiro, áspero ou espinhento".

O marcador "sertão" foi recuperado pela modulação backlands e pela explicitação rough country. O adjetivo rough, definido no Dicionário Inglês-Português Houaiss como "áspero, rugoso, caloso, irregular, acidentado, desigual”, confere ao vocábulo country as características do sertão nordestino.

Os MCs "guará”, “fogopagou” e "gaiamum” designam animais que habitam o nordeste brasileiro. O marcador "guará", de acordo com o Novo Aurélio, refere-se a uma espécie de mamífero carnívoro, canídeo, que habita nos cerrados nordestinos, de coloração pardo-avermelhada, mais escura no dorso, pés e focinhos pretos, com mancha branca na garganta, mede aproximadamente $1,45 \mathrm{~m}$ de comprimento e $45 \mathrm{~cm}$ de cauda, alimenta-se de pequenos mamíferos, aves e frutas; foi traduzido por meio da modulação com explicitação wild dog.

O marcador "fogopagou", traduzido no texto de chegada pela modulação scaled dove e pigeon, é definida no dicionário como uma ave de cor acinzentada que recebe esse nome devido ao som de seu canto.

"Gaiamum” não consta no dicionário Aurélio, mas pudemos depreender seu significado pela opção do tradutor, a explicitação land crab, ou seja, é o caranguejo do mangue, usado na alimentação do nordestino e, para alguns habitantes, é meio de sustento.

Os três últimos MCs do domínio ecológico selecionados para análise são espécies de plantas da vegetação nordestina. "Quixabeira”, "macambira” e "mandacaru”, recuperadas respectivamente pela adaptação bumelia, pela explicitação brown bushes e pela modulação cactus; são plantas diferentes, mas com alguns 
aspectos em comum, todas são espinhosas e servem de alimento para a região pobre do nordeste. A “quixabeira” é uma espécie de arvore pequena e o "mandacaru” é uma espécie de cacto, ambos servem de alimento ao gado na época da seca. A “macambira”, conforme o Novo Aurélio, refere-se a uma espécie de planta, cujas folhas são usadas como forro, ou para preparo de pão, sem valor nutritivo.

Os MCs do domínio material aparecem descrevendo objetos usados para a realização de determinadas tarefas relacionadas ao trabalho, ou ainda representando alimentos e bebidas próprios da região nordestina. Selecionamos para a análise três MCs que representam instrumentos utilizados para o trabalho: “embornal”, "pajeú” e "manguá"; três MCs que representam bebidas fortes feitas e comumente consumidas pelos sertanejos da região nordestina: "jurubeba", "catuaba” e "mundureba"; e três que representam a culinária específica da região: "beiju”, “jabá” e "pirão”. A Tabela 4 mostra esses marcadores e suas ocorrências em nosso corpus de estudo:

\section{TABELA 4 - OPCÕES DE TRADUCÃO PARA MCs DO DOMÍNIO} MATERIAL

\begin{tabular}{l|c|l|c}
\hline $\begin{array}{l}\text { MCs em Sargento } \\
\text { Getúlio }\end{array}$ & Ocorrências & MCs em Sergeant Getulio & Ocorrências \\
\hline EMBORNAL & 1 & SADDLEBAG & 1 \\
\hline PAJEÚ & 1 & BLADE & 1 \\
\hline MANGUÁ & 4 & WHIP & 4 \\
\hline CATUABA & 1 & FIREWATER & 1 \\
\hline JURUBEBA & 1 & POP SKULLS & 1 \\
\hline MUNDUREBA & 1 & TONIC & 1 \\
\hline BEIJU & 4 & TAPIOCA PIE & 1 \\
& & PIE & 3 \\
\hline JABÁ & 2 & CHEAP JERKED BEEF & 2 \\
\hline PIRÃO & 6 & MANIOC MUSH & 3 \\
& & MUSH & 2 \\
\hline
\end{tabular}

O “embornal", no contexto do texto de partida, é usado pelo cangaceiro Lampião. Segundo o Novo Aurélio, esse MC refere-se a um tipo de bolsa, comumente usada para carregar alimento para o trabalho. Essa é uma particularidade que o diferencia de saddlebag, que na língua de chegada está mais relacionado a um tipo de bolsa para transporte de outras coisas.

A "pajeú", de origem tupi, é definida nesse mesmo dicionário como uma faca grande, de ponta, de cabo de chifre, em forma de anéis brancos e pretos. Pode-se perceber, ao longo do texto, que os nordestinos têm predileção por facas, que aparecem representadas por: "peixeira”, "lambedeira”, etc. Existe uma região bastante conhecida no nordeste, no princípio habitada por indígenas, os pajeús, que confeccionavam esse tipo de faca. Hoje, "pajeú” é uma designação comum a instrumentos de cutelaria fabricados nos sertões de Pajeú. No contexto em análise, essas facas representam perigo; são referidas como armas e símbolo de força. O tradutor optou pela modulação blade na tradução, que corresponde a um hiperônimo. Verificamos no corpus de língua geral BNC, por meio das linhas de concordâncias, que esse vocábulo aparece, geralmente, com sentido de ferramenta de corte, ou como a lâmina que faz parte da ferramenta. 
O "manguá", definido no dicionário Novo Aurélio como uma correia com que se açoitam os animais, foi traduzido pela modulação whip. No texto de partida, é usado não apenas para açoitar animais, mas também para punir algumas personagens. É um instrumento rústico, que faz parte do dia-a-dia de trabalho do sertanejo, e também é utilizado de forma violenta, para repreensão e para mostrar força.

"Jurubeba”, “catuaba” e "mundureba” são vocábulos que representam bebidas fortes, comumente preparadas e consumidas na região nordestina. As duas primeiras, de origem tupi, são preparadas com plantas próprias da região; são consideradas medicinais, no caso da jurubeba, e como afrodisíaca, no caso da catuaba. A terceira significa cachaça. Para esses MCs, o tradutor optou pelas adaptações firewater, pop skulls e tonic, respectivamente. Dessa forma, o leitor da língua de chegada pode perceber tratar-se de bebida alcoólica, mas, pela falta de um correspondente na cultura de chegada, não pode recuperar o sentido medicinal que esses marcadores têm na língua de partida.

A culinária nordestina traz pratos específicos, tanto por serem feitos com os recursos, às vezes escassos, quanto pela influência das origens dos povos que formaram a região: índios, africanos, europeus. Os MCs "beiju”, “pirão” e “jabá” revelam um pouco dessa diversidade. O "beiju" é um tipo de bolo de massa de tapioca ou de mandioca, do qual há numerosas espécies, de acordo com a definição do dicionário Aurélio. A tapioca e a mandioca, de origem tupi, embora tenham muitas características em comum, são espécies diferentes de plantas. Esse marcador foi traduzido como tapioca pie na primeira vez e por pie nas outras três vezes, ou seja, na primeira vez o tradutor explicitou que era uma torta diferente, feita de tapioca, que não tem correspondente na cultura de chegada. A partir de então passou a usar a modulação pie.

O “pirão” é um prato de origem indígena tradicional no Brasil, à base de farinha de mandioca. Preparado com diferentes caldos, é tradicionalmente usado no acompanhamento de pratos à base de peixe. Na obra em estudo, o pirão não acompanhava somente os pratos de peixe, mas também pratos feitos com carne seca. O tradutor usou três formas diferentes em inglês: a explicitação com modulação manioc mush, a modulação mush e a implicitação something to eat. O vocábulo mush significa algo que foi cozido até desmanchar, conforme o dicionário Longman. O vocábulo manioc, no mesmo dicionário, consta como uma farinha feita de uma planta tropical, no caso, a mandioca. O tradutor explicitou o sentido do MC, criando uma imagem do pirão, um cozido feito com farinha de mandioca.

O “jabá” é definido no Novo Aurélio como a carne de vaca, salgada e em mantas. Em alguns lugares do nordeste, a carne é mantida dessa forma, devido à falta de recursos financeiros ou de energia elétrica. Ela se tornou comum na região, e mesmo onde há condições de conservação da carne, as pessoas preparam pratos com jabá por gostarem do seu sabor. A opção do tradutor para transpor esse marcador foi a explicitação cheap jerked beef, o que pode trazer uma imagem de inferioridade, talvez por não ser carne fresca, e por ser própria das regiões mais pobres.

Os marcadores culturais do domínio ideológico aparecem em pequena quantidade, conforme mostra a Tabela 5, a seguir: 
TABELA 5 - OPCÕES DE TRADUÇ̃̃O PARA MCs DO DOMÍNIO IDEOLÓGICO

\begin{tabular}{l|c|l|c}
\hline $\begin{array}{c}\text { MCs em Sargento } \\
\text { Getúlio }\end{array}$ & Ocorrências & MCs em Sergeant Getulio & Ocorrências \\
\hline $\begin{array}{l}\text { DRAGÃO } \\
\text { MANJALÉU }\end{array}$ & 3 & BOGEY DRAGON & 3 \\
\hline CAIPORA & 1 & BUGBEAR & 1 \\
\hline CÃO & 1 & DEVIL & 1 \\
\hline BICHO & 3 & CREATURE & 1 \\
& & DEVIL & 1 \\
& & ANIMAL & 1 \\
\hline
\end{tabular}

Os marcadores que foram classificados como ideológicos são aqueles que representam entidades religiosas e mitológicas ou a elas relacionadas. Aparecem em nosso corpus de estudo apenas os marcadores “manjaléu”, “caipora”, “cão” e "bicho”.

Durante o monólogo, o narrador personagem, Sargento Getúlio, vive um conflito interior, e apresenta, em alguns momentos, um fluxo de consciência cheio de delírios. "Manjaléu" é uma entidade folclórica do nordeste, que representa um monstro imaginário com que se faz medo nas crianças. Em seus delírios, Getúlio Santos Bezerra imagina-se aterrorizante como um dragão manjaléu. O tradutor optou pela adaptação bogey dragon para representá-lo.

"Caipora” é definido no dicionário Aurélio como um ente fantástico, que mora no mato, oriundo da mitologia tupi, representado, segundo as regiões, ou como uma mulher unípede que anda aos saltos, ou como uma criança de cabeça muito grande, ou como um caboclinho encantado, ou como um homem agigantado, montado em um porco do mato, ou com um pé só. Esse marcador também surge em um dos delírios do narrador personagem, que se sente só, e sabe que vai morrer. Neste momento, delira entre o mundo real e o espiritual. A opção do tradutor, bugbear, é uma adaptação, e não corresponde exatamente a essa entidade fantástica, mas representa algo que traz as sensações de ansiedade, medo e preocupação que o caipora aos quais o caipora remete.

Os MCs "cão" e "bicho" representam o diabo. Os nordestinos costumam contar estórias sobre aparições do diabo. Há um momento na narrativa em que Getúlio conta uma história, na qual uma tia viu o diabo. Para traduzir o MC “cão", o tradutor usou devil, e para "bicho", ele optou por creature, devil e animal. As formas creature e animal não são comumente usadas em inglês para representar o diabo; o tradutor buscou uma adaptação, e com isso pode ter revelado ao leitor da cultura de chegada a maneira particular como nos referimos a essa entidade espiritual.

\section{Comentários finais}

A obra Sargento Getúlio apresenta marcas de especificidade cultural relacionadas à ecologia, à culinária, a objetos utilizados na região, à linguagem característica do nordestino, bem como ao conjunto de valores e crenças que retratam o modo de pensar e de agir do sertanejo. Essas peculiaridades constituem um desafio para o tradutor, e requerem grande esforço para transmitir para leitor de outra língua e cultura, todo o contexto, o estilo e "sabor" do original. 
O autotradutor tem uma condição privilegiada por ser o autor do texto de partida, e poder conhecer melhor as próprias intenções. A interpretação de muitos aspectos do texto de partida poderia representar obstáculos maiores para um tradutor nativo da língua de chegada, dado o grau de complexidade da obra.

Buscamos observar, neste estudo, a forma como João Ubaldo Ribeiro superou tais dificuldades. Percebemos um alto grau de liberdade por parte do autotradutor, que recorreu, na maior parte das vezes, às modalidades de tradução oblíqua, como modulação, explicitação, e adaptação para traduzir os marcadores culturais analisados. Tais escolhas evidenciam sua preocupação com a fluência do texto de chegada, que, por sua vez, pode propiciar uma maior aceitabilidade da obra na comunidade de chegada.

Verificamos, também, que João Ubaldo Ribeiro utiliza, na maior parte das vezes, a mais de uma forma para traduzir um mesmo marcador. Isso se deve, além de uma maior liberdade que a posição de autotradutor lhe proporciona, ao fato de ter um domínio notável no idioma inglês. Sergeant Getulio recebeu elogios da crítica nos Estado Unidos, sendo que, na época de sua publicação, a obra ficou mais conhecida no exterior do que no Brasil.

\section{Referências}

AUBERT, Francis H. A tradução do intraduzível. Pesquisa apresentada a FFLCH, USP, 1981.

. Descrição e quantificação de dados em Tradutologia. Tradução e Comunicação, v. 4. São Paulo: Álamo, 1984.

. A fidelidade no processo e no produto do traduzir. Trabalhos em Linguística Aplicada, v. 14. Campinas, p. 115-229, 1989.

As (in)fidelidades da tradução - servidões e autonomia do tradutor. Campinas: Ed. UNICAMP, 1993.

. Desafios da tradução cultural (as aventuras tradutórias do Askeladden). TradTerm, n. 2. São Paulo: USP/FFLCH/CITRAT, p. 31-44, 1995.

Modalidades de tradução: teoria e resultados. TradTerm. n. 5. São Paulo: USP/FFLCH/CITRAT, p. 99-128, 1998.

BAKER, Mona. Corpus Linguistics and translation studies: implications and application. In: BAKER, Mona; FRANCIS, Gill; TOGNINI-BONELLI, Elena (Eds.). Text and technology: in honour of John Sinclair. Amsterdam/Philadelphia: John Benjamins Publishing Co., 1993. p. 233-250.

Corpora in Translation Studies: an overview and some suggestions for future research. Target, v. 7, n. 2, p. 223-243, 1995.

Corpus-based translation studies: the challenges that lie ahead. In: SOMER, Harold. Terminology, LSP and Translation Studies in language engineering: in honour 
of Juan C. Sager. Amsterdam/Philadelphia: John Benjamins Publishing Co., 1996. p. 177-243.

Linguística e estudos culturais: paradigmas complementares ou antagônicos nos Estudos da Tradução? In: MARTINS, Márcia A. P. (Org.). Tradução $e$ multidisciplinaridade. Tradução de Márcia A. P. Martins e Patrícia Broers-Lehmann. Rio de Janeiro: Lucença, 1999, p. 15-34.

. Toward a methodology for investigating the style of a literary translator. Target. v. 12, n. 2, p. 241-266, 2000.

BERBER SARDINHA, Tony. Lingüística de corpus. Barueri: Manole, 2004.

CAMARGO, Diva C. As modalidades tradutórias e a tipologia textual: uma via de abordagem para uma tipologia de tradução interlingual. 1993. Tese (Doutorado em Estudos da Tradução) - Universidade de São Paulo, FFLCH, USP, 1993.

Padrões de estilo de tradutores: um estudo de semelhanças e diferenças em corpora de traduções literárias, especializadas e juramentadas. 2005. Tese (Livre Docência em Tradução) - Instituto de Biociências Letras e Ciências Exatas, Universidade Estadual Paulista, São José do Rio Preto, 2005.

Metodologia de pesquisa em tradução e lingüística de corpus. São Paulo: Cultura Acadêmica; São José do Rio Preto, São Paulo: Laboratório Editorial do Ibilce, UNESP, 2007.

FERREIRA, Aurélio B. H. Novo Aurélio Século XXI: o dicionário da língua portuguesa. Rio de Janeiro: Nova Fronteira, 1999.

HOUAISS, Antonio. Dicionário Inglês-Português Houaiss. Rio de Janeiro: Record, 2005.

LONGMAN GROUP UK LIMITED. Longman dictionary of English and culture, 1992.

MIYASAKI, Tieko Y. Um tema em três tempos. João Ubaldo Ribeiro, João Guimarães Rosa, José Lins do Rego. São Paulo: Fundação Editora da Universidade Estadual Paulista, 1996.

NIDA, Eugene. Linguistic and ethnology in translation problems. Word, v. 1.2, p. 194208, 1945.

RIBEIRO, Evelin. L. P. Um estudo de marcadores culturais da obra An Invincible Memory pelo autotradutor João Ubaldo Ribeiro. 161f. 2005. Dissertação (Mestrado em Estudos Lingüísticos: Lingüística Aplicada) - Instituto de Biociências Letras e Ciências Exatas, Universidade Estadual Paulista, São José do Rio Preto, 2005.

RIBEIRO, João. U. Sargento Getúlio. Rio de Janeiro: Nova Fronteira, 1971. 
Sergeant Getulio. Tradução de João Ubaldo Ribeiro. Boston: Houghton Mifflin Company, 1978.

SCOTT, Mike. WordSmith Tools, versão 4.0. Oxford University Press.

VINAY, Jean-Paul. La traducción humana. In: MARTINET, André. Tratado del Lenguaje. v. 4. Buenos Aires: Nueva Visión, 1976. Tradução para Espanhol de André Martinet. Le Langage. Paris, Gallimard, 1968.

; DARBELNET, Jean. Stylistique comparée du Français e de l'Anglais. Paris, Didier, 1958, 1977. Tradução de Juan C. Sager: Comparative stylistics of French and English: a methodology for translation. Amsterdam; Filadélfia: John Benjamins, 1995. 